\title{
Post-fundoplication high-resolution esophageal manometry in a patient with Ehlers-Danlos syndrome
}

\author{
Vignesh Ramachandran ${ }^{a *}$, Kevin P. Shah ${ }^{a *}$, Douglas S. Fishman ${ }^{a, b}$, Eric H. Chiou ${ }^{a, b}$ \\ Baylor College of Medicine; Texas Children's Hospital, Houston, Texas, USA \\ ${ }^{*}$ Contributed equally
}

A 10-year-old boy with developmental delay and EhlersDanlos syndrome (EDS) presented with gastroesophageal reflux disease refractory to acid suppression therapy. Esophagogastroduodenoscopy revealed esophagitis, while multichannel $\mathrm{pH}$-impedance monitoring confirmed elevated esophageal acid exposure. Nissen fundoplication was subsequently performed. Three weeks postoperatively, the patient reported worsening dysphagia for both solids and liquids. A contrast esophagogram showed intact fundoplication, but delay of contrast passing through a markedly narrow channel. Endoscopic balloon dilatation of the esophagogastric junction (EGJ) to $15 \mathrm{~mm}$ was completed, but dysphagia symptoms persisted. High-resolution esophageal manometry (HREM) confirmed the presence of persistent EGJ outflow obstruction despite prior dilation (Fig. 1), as reflected by an elevated mean integrated relaxation pressure (IRP) of $30.6 \mathrm{mmHg}$ and elevated intrabolus pressure of $15.4 \mathrm{mmHg}$. Esophageal body peristalsis and upper esophageal sphincter motility were normal. Repeat balloon dilatation to $20 \mathrm{~mm}$ was performed and resulted in improvement in dysphagia.

In adults with persistent dysphagia after Nissen fundoplication despite normal endoscopic findings, HREM has been used to show an association between outflow resistance (measured by a longer length of distal esophageal highpressure zone and increased IRP) and dysphagia compared to asymptomatic patients [1]. EDS patients commonly suffer from gastrointestinal disorders, such as gastroesophageal reflux disease, that require Nissen fundoplication. However, these

a'Baylor College of Medicine (Vignesh Ramachandran, Kevin P. Shah, Douglas S. Fishman, Eric H. Chiou); ${ }^{\mathrm{b}}$ Department of Gastroenterology, Hepatology, and Nutrition, Texas Children's Hospital (Douglas S. Fishman, Eric H. Chiou), Houston, Texas, USA

Conflict of Interest: None

Correspondence to: Eric H. Chiou, Assistant Professor of Pediatrics, 6701 Fannin St. Mark Wallace Tower 1010.00 Houston,

TX 77030, USA, e-mail: ehchiou@texaschildrens.org

Received 19 June 2018; accepted 30 June 2018; published online 19 July 2018

DOI: https://doi.org/10.20524/aog.2018.0294

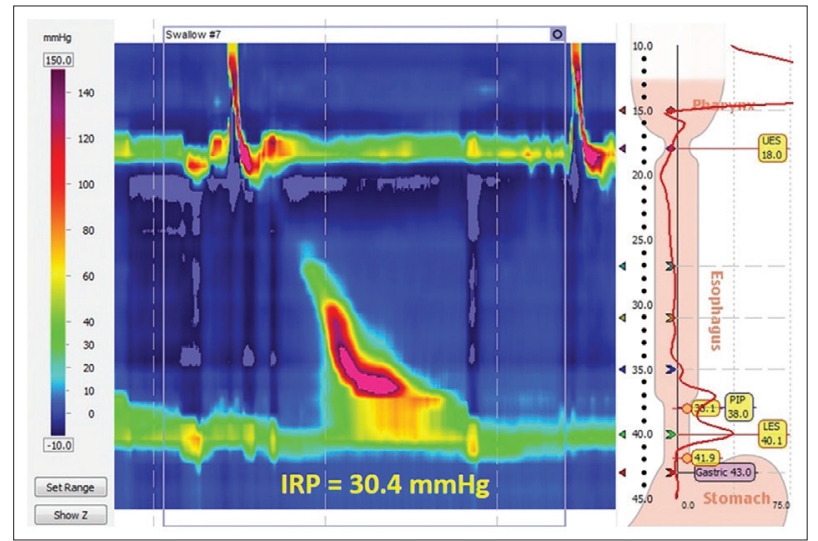

Figure 1 Representative example of a swallow with functional esophagogastric junction obstruction. Note the elevated integrated relaxation pressure at the esophagogastric junction and the slight compartmentalized pressurization in the distal esophagus during peristalsis

patients are at higher risk of endoscopy-related complications, including perforation from excessive dilatation [2]. Thus, HREM can be helpful to confirm EGJ obstruction postfundoplication, especially when considering more aggressive dilation in high-risk patients [3]. The role of HREM in evaluating the status of children post fundoplication has not previously been reported.

\section{References}

1. Yamamoto SR, Akimoto S, Hoshino M, Mittal SK. High-resolution manometry findings in symptomatic post-Nissen fundoplication patients with normal endoscopic configuration. Dis Esophagus 2016;29:967-970.

2. Nelson AD, Mouchli MA, Valentin N, et al. Ehlers Danlos syndrome and gastrointestinal manifestations: a 20-year experience at Mayo Clinic. Neurogastroenterol Motil 2015;27:1657-1666.

3. Marjoux S, Roman S, Juget-Pietu F, et al. Impaired postoperative EGJ relaxation as a determinant of post laparoscopic fundoplication dysphagia: a study with high-resolution manometry before and after surgery. Surg Endosc 2012;26:3642-3649. 